\title{
WORD-FINAL STOPS IN BRAZILIAN PORTUGUESE ENGLISH: ACQUISITION AND PRONUNCIATION INSTRUCTION
}

\author{
Walcir Cardoso \\ Concordia University \& the Centre for the Study \\ of Learning and Performance, Canada
}

\section{Abstract}

This paper presents current research on the second language acquisition of English phonology and its implication for (and applications to) pronunciation instruction in the language classroom. More specifically, the paper follows the development of English word-final consonants by Brazilian Portuguese speakers learning English as a foreign language. The findings of two parallel studies reveal that the acquisition of these constituents is motivated by both extralinguistic (proficiency, style) and linguistic (word size, place of articulation) factors, and that the process is mediated by an intermediate stage characterized by consonant lengthening or aspiration (Onset-Nucleus sharing). Based on these results, I propose that the segments and environments that seem to delay coda production (i.e., monosyllabic words, labial and dorsal consonants) should be given priority in pronunciation instruction. Along the lines of Dickerson (1975), this paper proposes (what we believe is) a more effective and socially realistic pedagogy for the teaching of English pronunciation within an approach that recognizes that "variability is the norm rather than the exception" in second language acquisition.

Keywords: Coda acquisition, pronunciation, ESL. 


\section{Introduction}

An inspection of current literature on the phonological acquisition of English as a second or foreign language (ESL) and textbooks that contain English pronunciation instruction reveals that the interaction between second language research and materials designed for ESL instruction is almost nonexistent. While research on second language (L2) phonology is replete with analyses that substantiate the claim that emergent L2 sound systems are systematic and therefore predictable just like mature, "full-fledged" languages (e.g., Archibald, 1998; Goad \& Kang, 2003), this knowledge is rarely reflected in classroom practices and in most of the textbooks used in TESL training (e.g., Avery \& Ehrlich, 1992; Celce-Murcia, Brinton, \& Goodwin, 1996) and to teach ESL pronunciation (e.g., Gilbert, 2005; Miller, 2000). In this context, this paper presents my current research on the acquisition of second language phonology and demonstrates how the knowledge obtained in these studies can be applied to pronunciation instruction in a language classroom environment.

The implications and applications of research on L2 phonological acquisition will be demonstrated in the context of two studies. These studies adopt standard sociolinguistic protocols for the elicitation of variable data, and follow the development of English singleton wordfinal stops (codas) by Brazilian Portuguese (BP) native speakers learning English as a foreign language in a classroom environment, across three levels of proficiency: beginners, intermediate and advanced. In general, the two studies address the following questions: (1) How systematic is the variation that is observed in the development of word-final singleton stops by BP speakers? (2) How does it change during the development of English? (3) What are the relative contributions of the linguistic and extralinguistic independent variables included in this study?

Based on the insights provided by both studies, I will discuss a number of implications for teaching the pronunciation of codas in English taking into consideration the roles of stylistic environment, 
word size, place of articulation and proficiency level. Finally, a number of traditional and computer-based activities (e.g., using the free programs ReadPlease for building sound awareness and Praat for training coda production via electronic visual feedback) will be provided in view of the findings outlined above.

The paper is organized in the following way. In section 2, I provide an introduction to codas in Brazilian Portuguese and BP-based interlanguages. Section 3 presents the results of the two abovementioned studies on the acquisition of English codas, and is followed by sections 4 and 5 , where I address, in that order, the research implications and applications of the results obtained in the studies. Finally, in section 5, I present the concluding remarks of the paper.

\section{Codas in Brazilian Portuguese and Brazilian Portuguese English}

In Brazilian Portuguese, only four consonants can potentially appear in coda position: /1/, /N/, /r/ and /s/. While /1/ and /N/ an underspecified nasal consonant) never surface as codas in most varieties of BP (see (1a) below), $/ \mathrm{r} /$ and / s/ are the only consonants that syllabify as codas in the language. Word-finally, however, these two consonants may variably undergo deletion in informal stylistic environments, as illustrated in (1b) (Cardoso, 1999).

(1) Codas in BP

a. Consonants that do not surface as codas

$/ 1 /:$ /brazil/ $\rightarrow$ [bra.'ziw] 'Brazil' (cf. [bra.zi.'lej.ru] 'Brazilian')

$/ \mathrm{N} /: /$ boN/ $\rightarrow$ [bõ] 'good' (cf. [bõ.na.'Jãw] 'good person')

b. Consonants that variably surface as codas

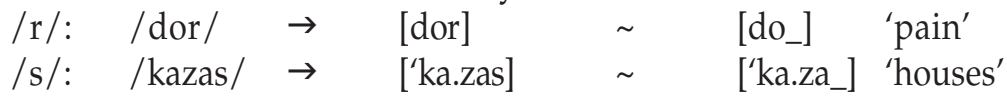

If the syllable-final consonant is an obstruent stop, BP opts for the syllabification of the illicit consonant as the onset of the epenthetic 
vowel [i] - i-epenthesis henceforth. This applies to both native (2a) and loan words $(2 b)$ :

(2) i-epenthesis in BP

a. BP native words:

/sub+zugar/ $\rightarrow \quad$ [su.bi.zu.'gar] 'to subjugate'

b. Loan words:

/hatdag/ $\quad \rightarrow \quad$ ['ho.tfi 'do.gi] 'hot dog'

In Brazilian Portuguese English (BPE, a cover term that I adopt here for convenience to describe the different interlanguage varieties encountered in the development of BP-based English), the language learner starts off from an initial stage in which the emergent grammar directly reflects the phonology of $\mathrm{BP}$ (i.e., illicit codas surface as onsets of epenthetic vowels; see (3a); where s indicates syllable boundaries, and the letters $\mathrm{R}, \mathrm{O}, \mathrm{N}$ and $\mathrm{C}$ represent the syllable constituents Rhyme, Onset, Nucleus and Coda respectively). As the learner progresses in the development of English phonology, one observes a phenomenon to which I will refer as Onset-Nucleus sharing (ONS, see (3b)), along the lines of Goad and Kang (2003). ONS can be described as a developmental process in which the melody of the word-final consonant spreads into a following nucleus. Phonetically, this phenomenon is characterized by fortition (overt release) or aspiration (represented here by a superscripted [h]), in accordance with Prator and Robinett's (1972, p. 89) observation that "[m]any students from abroad try to pronounce final consonants with a great deal of force. This may sound like aspiration [...]. The little puffs of air after $/ \mathrm{t} / \mathrm{and} / \mathrm{k} /$ sound like extra syllables". It is important to mention that ONS is not an idiosyncrasy of BP-based English. The aspiration that characterizes ONS has also been observed in adult languages (e.g., Yapese: Jensen, 1977), in first language (L1) acquisition (e.g., English: Leopold, 1939; Quebec French: Rose, 2000), and in L2 acquisition (e.g., Korean English: Goad \& Kang, 2003; Mandarin English: Heyer, 1986). Finally, the last stage in the 
acquisition of English codas is one that resembles that of the target language, in which codas may appear freely, as illustrated in (3c).

\begin{tabular}{|c|c|c|c|c|c|c|}
\hline \multicolumn{3}{|c|}{ (3) a. i-epenthesis } & \multicolumn{2}{|c|}{ b. O-N sharing } & \multicolumn{2}{|l|}{ c. Coda } \\
\hline & & $\sigma$ & & $\sigma$ & $\sigma$ & \\
\hline $\mathrm{N}$ & $\mathrm{O}$ & $\mathrm{N}$ & $\mathrm{N}$ & $\mathrm{O} \mathrm{N}$ & $\mathrm{O}$ & $C$ \\
\hline I & & $\mathrm{i}$ & I & $\mathrm{p}$ & I & $\mathrm{p}$ \\
\hline
\end{tabular}

The distribution of i-epenthesis, ONS and coda production in the acquisition of English phonology is not as simple and clear-cut as implied above: the development of codas in interlanguage is variable. While one may correctly predict that ONS is more likely to occur in intermediate stages of English acquisition, these stages are also characterized by instances of both i-epenthesis and target-like codas. In the following section, I will demonstrate that variability in the development of English codas is systematic (and based on some language universals, also predictable) and results from the interaction of both linguistic and extralinguistic factors as well as transfer from BP phonology.

\section{The development of codas in Brazilian Portuguese English: two studies}

This section will address two studies that were conducted in order to establish what linguistic and extralinguistic factors have an effect on variability in the development of English codas by BP speakers.

\subsection{Study One (Cardoso, in print).}

The questions addressed in the first study were: (1) at what proficiency level is Onset-Nucleus sharing acquired and when does it 
develop into full codas? (2) What are the relative contributions of style in the development of codas?

The data consisted of 1,208 tokens of word-final stops, collected in the field by the author in the city of Belém, in northern Brazil. The methodology for data elicitation was a picture-naming task, inspired by Labov's (1966) study on the /r/ variable in New York City: participants were shown pictures of objects and animals (e.g., book, cat) and were asked to orally name what was depicted on the picture. For convenience, these utterances were coded as "Informal: spontaneous speech". In order to obtain more careful samples of the same tokens, the researcher pretended not to hear the participants' initial response (either by asking a variant of "sorry, can you say that again?" or using body language). The tokens collected as answers to the second question were coded as "Formal: careful speech" as they reflect the amount of time available for planning of pronunciation. To distract the participants away from the purpose of the task, picture-naming and repetition questions were usually intermingled with more general questions about the participant. The interviews were audio recorded via a Marantz CDR300 CD/RW Recorder and an Audio-Technica AT831b lavaliere microphone, and later transcribed for statistical analysis with the assistance of two research assistants.

The data collected from 60 participants (20 per proficiency group) were stratified among two independent variables: (1) level of formality (Informal and Formal, as outlined above); and (2) level of proficiency (Level 1: beginners, Level 2: intermediate, Level 3: advanced). The dependent variables were: i-epenthesis, Onset-Nucleus sharing and coda production. The data were later analyzed by the VARBRUL statistical program (Pintzuk, 1988).

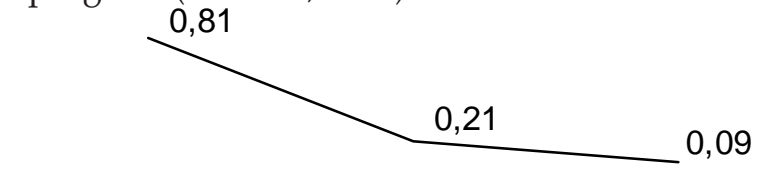

Level 1

Level 2

Level 3

Figure 1. i-epenthesis across three proficiency levels (VARBRUL weights). 


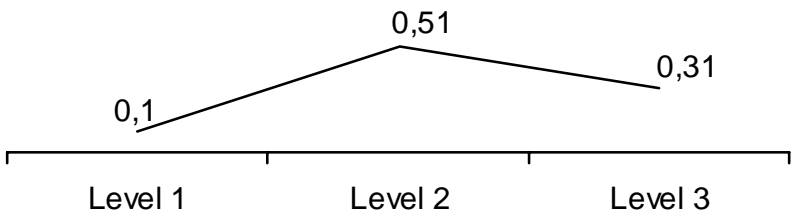

Figure 2. O-N Sharing across three proficiency levels (VARBRUL weights).

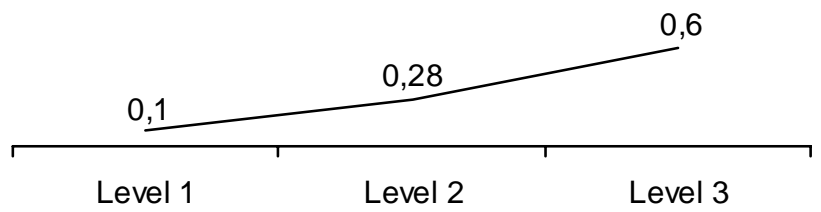

Figure 3. Coda development across three proficiency levels (VARBRUL weights).

Figures 1, 2 and 3 illustrate the VARBRUL statistical results that address the first research question. Comparing Figure 1 with Figure 3, observe that while in the former the BP-based transfer phenomenon of i-epenthesis decreases with exposure to L2 English, in the latter, the production of codas increases as a function of increased L2 proficiency. Onset-Nucleus sharing (depicted in Figure 3), on the other hand, initially increases and then decreases with greater proficiency, illustrating a developmental pattern that is usually associated with developmental phenomena observed across languages and in the acquisition of first and second languages, as discussed in section 2 . These findings are in accordance with the predictions by Major's (2001) Ontogeny Phylogeny Model of second language acquisition, which maintains that L1 transfer features (e.g., i-epenthesis) occur at a considerably high rate at the beginning stages and decrease as learners become more proficient in the L2, with the complete reverse pattern for L2 features (e.g., coda production; compare Figure 1 with Figure 3 below). With regards to developmental features such as ONS, the Model predicts that their rate will steadily rise and then descend over exposure to an L2 (see Figure 2). 
The effects of style on the three stages that characterize the development of codas in BPE are illustrated in Figure 4. The VARBRUL statistical analyses indicate that, across the three levels of proficiency included in the study, i-epenthesis is a characteristic of more informal stylistic environments, while ONS and coda production (in increasing order of likelihood) can be described as features of more formal contexts - those that require more careful and planned speech.

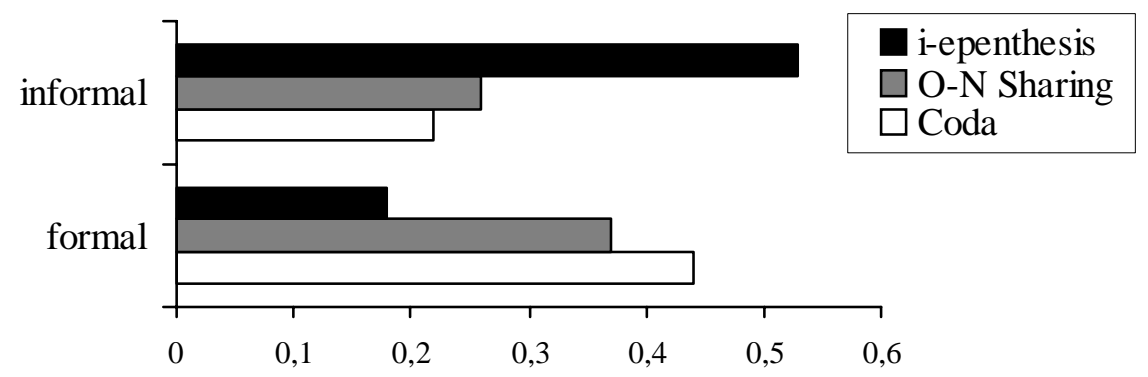

Figure 4. Word-final voiceless stops and their syllabification across styles: Informal and Formal (VARBRUL weights).

So far, we have established that the development of English codas across three stages of acquisition is motivated by level of proficiency and stylistic environments. Let us now turn to the second study, where it is shown that the development of codas in BPE is also motivated by internal, linguistic factors.

\subsection{Study Two (previously published; Cardoso, 2007).}

This study addressed the following questions: (1) what is the contribution of place of articulation (i.e., labial, coronal, and dorsal) in the development of codas? (2) What is the contribution of word size (monosyllabic vs. polysyllabic words; e.g., "dog" vs. "wanted" respectively) in the development of codas? More specifically, these questions aim to find out what linguistic factors facilitate or hinder the production of codas. 
As was the case for Study 1, Study 2 followed standard sociolinguistic protocols for data collection and analysis. This study consisted of 1,859 tokens of word-final stops, also collected in the field by the author in the city of Belém, Brazil, and included two dependent variables: target-like production of word-final stops (coda) and i-epenthesis (BP transfer). As is standard in variationist studies, the data collected were stratified among a number of standard linguistic and extralinguistic factors that were later analyzed by the VARBRUL statistical program. For this study, I will only report and discuss the results for the two relevant factors: (1) place of articulation of the word-final stop (coronal [ $t d$ ], labial [p b] or dorsal [k g]); and (2) word size (one versus more than one syllable). The participants consisted of six native speakers of BP (three male and three female, with an average age of twenty-one) learning English as a foreign language in a classroom environment. The six participants represented three distinct proficiency levels (two beginners, two intermediate, and two advanced). For more information on the methodology adopted and the factors investigated, see Cardoso (2007).

The relevant VARBRUL results are provided in Figures 5 and 6 below. Figure 5 shows that, of the three sets of place of articulation considered in this study, coronal word-final stops (i.e., [t d]) are more likely to surface as target-like codas in BP English. Because consonant deletion is not an option in the phonology of BP English, labials $[p, b]$ and dorsals $[k, g]$ are more likely to either undergo iepenthesis or syllabify as Onsets (via ONS) in order to surface in Interlanguage. This behavior can be explained by the markedness sub-hierarchy of place of articulation (Prince \& Smolensky, 1993), which maintains, based on cross-linguistic observation, that labial and dorsal codas are more marked than their coronal counterparts. Being less marked than labials and dorsals, coronals are the best candidates to syllabify as target-like codas in BP-based Interlanguage. 


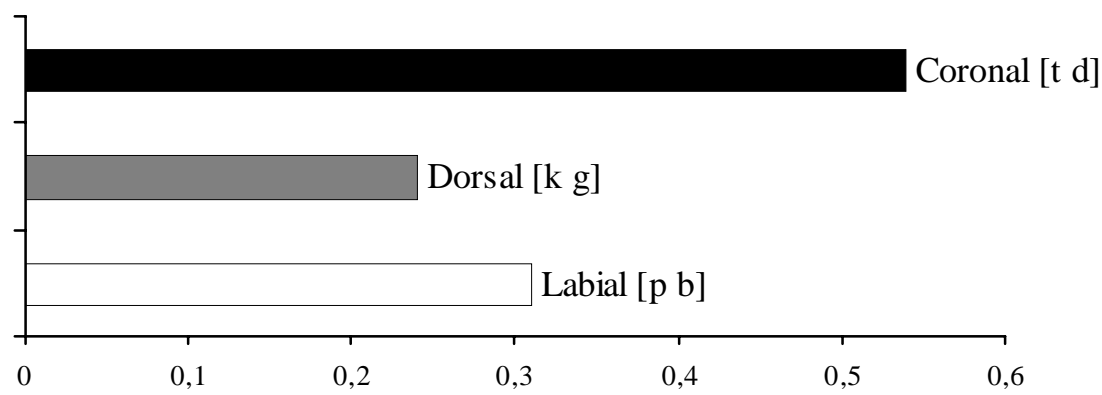

Figure 5. (Target-like) coda development by Place of Articulation (VARBRUL weights).

The results involving the factor word size are illustrated in Figure 6. Observe that word-final stops are more likely to surface as targetlike codas if they appear in polysyllabic words (e.g., [kə.'mit] "commit" is more likely than [kə.'mi.ti]. A corollary of this statement is to say that i-epenthesis is more frequent in monosyllabic words (e.g., ['da.gi] is more likely than [dag] 'dog'), a pattern that clearly reflects the crosslinguistic tendency for words to contain minimally two syllables (e.g., Wang, 1995; Everett, 1996; Broselow et al; 1998). Interestingly, this tendency is not a peculiarity of BPE: it has been observed across languages (e.g., Ussishkin, 2000), in L1 acquisition (e.g., Tzacosta, 2003), and in the development of other second languages (e.g., Wang, 1995; Broselow et al; 1998).

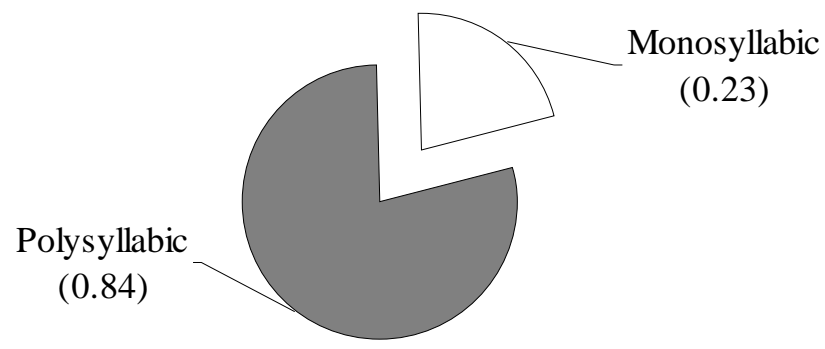

Figure 6. (Target-like) coda development by Word Size (VARBRUL weights). 
The implications and pedagogical applications of these results to pronunciation instruction in a language classroom will be discussed in the following section.

\section{Research implications}

The studies discussed in the previous section have shown that the acquisition of codas by Brazilian Portuguese speakers is a variable (albeit systematic) process that can be described via a combination of linguistic and extralinguistic factors. A summary of the results obtained in Section 2 is provided below, followed by a discussion of what their implications are for the teaching of pronunciation:

Result 1: The acquisition of codas involves three developmental stages: i-epenthesis, Onset-Nucleus sharing and target-like coda production. The teacher or materials designer should design activities that highlight the (inevitable) intermediate stage characterized by ONS, for instance, by lengthening (or in the case of voiceless stops, aspirating) the pronunciation of word-final stops and asking the students to do likewise when producing these consonants. This type of "focus on form" will provide learning opportunities that will assist in both the perception and production of the target coda.

Result 2: Coda production increases with exposure to the second language. The teacher should be aware that "errors" are part of the learning process and that change in phonology is gradual, predictable and systematic (see forthcoming discussions). When a beginning student says "I washed the dog[i]", the teacher should understand that this is just a phase in the development of the target language and that this particular consonant (i.e., the dorsal [g]) in a monosyllabic word is of particular difficulty to the language learner. With adequate training and exposure to English, the learner will eventually master the phonological system that characterizes the target language. 
Result 3: The development of codas is sensitive to stylistic environment: ONS and codas are characteristics of formal stylistic environments. The study has shown that students behave differently depending on the amount of attention given to speech. For instance, while an advanced student may say "I drew a ship [i]" when engaged in informal activities (e.g., role-playing, talking to colleagues), the same student may also say "I drew a shi[p]" or "I drew a shi[p $\left.\mathrm{p}^{\mathrm{h}}\right]$ " when engaged in more formal activities (e.g., reading a text aloud). As a result, the teacher should only evaluate pronunciation (e.g., of a group of ESL students) in oral exchanges that take place within a single style (e.g., a more formal reading aloud task vs. a less formal role-playing activity) because different styles lead to different outcomes in performance. If a teacher, for instance, evaluates the oral proficiency of an ESL student engaged in a task that is at one of the ends of the stylistic spectrum (e.g., in an informal oral interaction with peers), and then evaluates another student involved in a task that is at the opposite end of the same spectrum (e.g., in a formal, reading aloud task), it is very likely that the production of codas among these two students will not be the same; a direct consequence of such a scenario is that it would compromise test validity. Note that I am not implying that informal interactions always lead to less target-like forms - there are studies that in fact show opposite trends (e.g., Beebe, 1980; Tarone, 1985; Edge, 1991; Major, 1994; Silveira, 2007). What I do suggest is that production (target-like or BP-influenced) is directly influenced by style, as this and the studies cited above illustrate.

Result 4: Monosyllabic words, labial and dorsal consonants hinder the acquisition of codas. Because of the relative markedness of monosyllabic words and labial and dorsal consonants in word-final position, language teachers and materials designers should prioritize them when creating pronunciation activities. Coronals and consonants in polysyllabic words, on the other hand, should not receive the same amount of attention in pronunciation activities since they are more likely to be produced as codas earlier in the acquisition process of these constituents in L2 English. 


\section{Classroom applications}

In this section, I will demonstrate that the results of the studies discussed in sections 2 and 3 are of practical relevance to the teaching of pronunciation in a classroom environment. I will provide a series of activities that target the development of English codas, going from an initial phase of building awareness to the existence of these syllable constituents, to a final phase that conforms to the concept of "communicative practice". In these activities, I follow some of CelceMurcia et al.'s (1996) recommendations for teaching pronunciation within a communicative framework.

Activity 1: Building sound awareness. This activity aims to alert students to the existence of codas as physical entities; therefore, meaning is not taken into consideration. Students will merely have to distinguish words that contain and those that do not contain the target consonant. For building awareness, I provide an adapted version of Taylor's (1993) YES/ NO game. In this activity, the teacher reads aloud a list of words, some of which end with a coda (e.g., make, tap, mood) and some with an [i] (e.g., copy, coffee, Becky). After each word, the students hold up one of their cards - YES if they think the word contains the given sound, and NO if not. When pronouncing each word, the teacher should put emphasis on the word-final consonant by lengthening (or in the case of voiceless stops, aspirating) its pronunciation. This will make the sound more perceptible and will prepare the students for the imminent stage of coda acquisition: the syllabification of these consonants as Onsets via ONS.

\section{An alternative: computer-based activity for building awareness and listening discrimination (via ReadPlease). If} students have access to computers, text-to-speech synthesizers such as ReadPlease (free download from www.readplease.com) can also be employed in activities that build sound awareness. After students download and install the free program ReadPlease in their computers, the teacher distributes a list of words (by e-mail, on a website or write 
them on the blackboard; e.g., cough, mold, pick, copy, Frank, coffee, Frankie, moldy, cop, picky). The teacher then provides a table with one column titled "Consonant ending" and the other "[i] ending", and asks students to copy and paste (or write) the word list onto the ReadPlease window and click on Play. The words will be read by the program (the student may pause during playback) and the student will have to identify which words go under each column. In the context of codas, one advantage of using text-to-speech synthesizers to build awareness is that, in these programs, word-final consonants are fully pronounced and rarely unreleased (note that the non-releasing of codas is a characteristic of natural, connected speech). This feature adheres to one of the assumptions and implications of this study, namely that the non-saliency of unreleased consonants could obstruct the development of codas because these consonants are not perceptually in evidence in the input.

Activity 2: Listening discrimination. Once students are able to recognize whether a given word ends in a consonant or in [i], they can proceed to an activity that aims to expose them to sound contrast discrimination, i.e., that [i] in "copy" ['kapi] conveys meaning in English and distinguishes it from "cop" [kap]. The proposed activity is a revised version of traditional "Minimal Pairs" exercises. The teacher distributes (or writes on the board) two-choice sentences from which the students are asked to select the alternative that completes each item, based on a story that the teacher reads (e.g., a narrative about a crime involving Frank and his wife). Examples of two-choice items: (1) The person needs a cop/copy; (b) Something that the person doesn't like: to cough/coffee; (c) The person's husband name is Frank/Frankie.

Activity 3: Controlled practice. At this stage, students should be able to discriminate sound contrasts between word-final consonants and those that end in [i]. The perceptual skills developed in the two previous activities should now be supplemented with pronunciation practices that focus on the production of codas. Tongue twisters provide a focused and effective alternative for the practice of specific 
pronunciation features. The following two examples were carefully selected because they include consonants that fit into one of the categories established as difficult for coda production. Observe that the word-final consonants occur in monosyllabic words and, for the most part, these consonants belong to one of the sets of marked segments (i.e., labials and dorsals): (1) "A bi $[g]$ blac [k] bu [g] bit a bi $[g]$ blac $[k]$ bear. Where's the bi[g] blac[k] bear the bi[g] blac[k] bu[g] bi[t]? (2) "Cho[p] sho[ps] stoc[k] cho[ps]".

\section{An alternative: computer-based activity for controlled} practice (via Praat). Several studies in the field of computer assisted language learning (CALL) have shown the effectiveness of using computers for teaching second language pronunciation (e.g., De Bot, 1983; Hardison 2004; Lambacher, 1999; Zhang, 2005). Inspired by these results, I will demonstrate in this activity how students can engage in pronunciation practice via electronic visual feedback using a program for speech analysis: Praat, Version 4.3 (Boersma \& Weenink, 2007). This program can be downloaded free of charge from www.fon.hum.uva.nl/ praat. Praat can record, play and display the waveforms and spectral information of any recorded sample (see the website for links to guides and tutorials on how to use Praat). For this activity, we will focus on waveforms because they serve the purpose of illustrating whether a segment was epenthesized or not.

Before we discuss the proposed activity, one would have to acknowledge that the effective use of Praat requires some basic computer knowledge and training on how to read waveforms for both teachers and learners. Let us turn to the activity. The teacher records in Praat a set of individual files containing consonant-final words (e.g., ship, played, dog) and sends them to the students (via e-mail attachments, post them on a website or distribute them on CDs). The students will open and listen to each audio file in Praat, and then record their own pronunciation for each word using the program. Both the teacher's and the students' recordings can subsequently be analyzed visually in Praat. Finally, the students compare the waveforms of their 
pronunciations with those of the teacher and arrive at their own conclusions regarding the production of the target consonants and whether it needs further improvement. To illustrate, consider the two waveforms for the English word "ship": target-like [SIp], illustrated in (4a), and ['SI.pi], produced by an English learner, shown in (4b). Observe that (4b) depicts a pronunciation containing an intrusive element that can be easily visualized: the epenthetic [i].

(4) Waveforms for [SIp] and ['SI.pi]

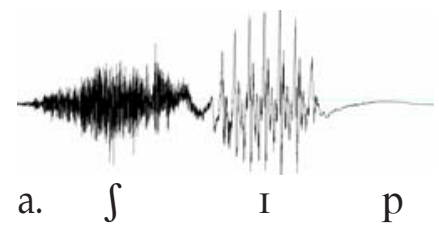

b.

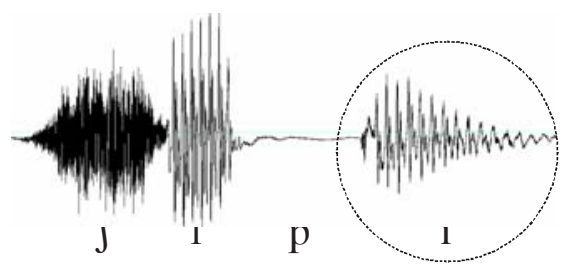

Activity 4: Communicative practice and feedback. At this stage, it is assumed that students are able to recognize, discriminate and variably produce word-final consonants. The activity described here will allow students to engage in more meaningful, communicative practice of the target consonant. In groups, students are asked to create a story (orally) using a set of words provided by the teacher, containing sets of minimal pairs involving consonant-final words and their [i]final counterparts (e.g., cough/coffee, cop/copy, Frank/Frankie, mold/ moldy, pick/picky). Students are then asked to present their stories. During presentation, the students in the other groups check whether the words were pronounced correctly according to the context.

\section{Conclusions}

This paper presented current research on the second language acquisition of English phonology and its implication for (and applications to) pronunciation instruction in the language classroom. More specifically, the paper followed the development of English codas 
by BP speakers. The findings of the two studies presented revealed that the acquisition of codas in Brazilian Portuguese English is motivated by both extralinguistic (proficiency, style) and linguistic (word size, place of articulation) factors, and that the process is mediated by an intermediate stage characterized by consonant lengthening or aspiration (Onset-Nucleus sharing). Based on these results, it was proposed that the segments and environments that seem to delay coda production (monosyllabic words, labial and dorsal consonants) should be given priority in pronunciation instruction. More importantly, along the lines of Dickerson (1975), this paper concluded that the acquisition of an L2 phonological system is an intrinsically variable and systematic process. Finally, the classroom applications of these results were demonstrated via a number of traditional and computer-based activities.

In sum, this paper has proposed a more effective and socially realistic pedagogy for the teaching of English pronunciation within an approach that recognizes that "variability is the norm rather than the exception" (Dickerson, 1975) in second language acquisition.

\section{References}

Archibald, J. (1998). Second language phonology. Amsterdam/Philadelphia: John Benjamins.

Avery, P. \& Ehrlich, S. (1992). Teaching American English pronunciation. Oxford: Oxford University Press.

Beebe, L. (1980). Sociolinguistic variation and style shifting in second language acquisition. Language Learning, 30, 433-447.

Boersma, P. \& Weenink, D. (2007). Praat: Doing phonetics by computer (Version 4.6.21) [Computer program]. Retrieved September 11, 2007, from http:// www.praat.org.

Broselow, E., Chen, S.-I. \& Wang, C. (1998). The emergence of the unmarked in second language phonology. Studies in Second Language Acquisition, 20, 261-280. 
Cardoso, W. (in print). A sociolinguistically-grounded approach to second language phonology: Onset-Nucleus sharing in Interlanguage and the acquisition of codas in Brazilian Portuguese English. Studia Linguistica.

Cardoso, W. (2007). The variable development of English word-final stops by Brazilian Portuguese speakers: A stochastic optimality theoretic account. Language Variation and Change, 19, 1-30.

Cardoso, W. (1999). A quantitative analysis of word-final / $\mathrm{r} /$-deletion in Brazilian Portuguese. Linguistica Atlantica, 21, 13-52.

Celce-Murcia, M., Brinton, D. \& Goodwin, J. (1996). Teaching pronunciation: A reference for teachers of English to speakers of other languages. New York: Cambridge University press.

de Bot, K. (1983). Visual feedback of intonation I: Effectiveness and induced practice behavior. Language and Speech, 26, 331-50.

Dickerson, L. J. (1975). The learner's interlanguage as a system of variable rules. TESOL Quarterly, 9 (4), 401-408.

Edge, B. A. (1991). The production of word-final obstruents in English by L1 speakers of Japanese and Cantonese. Studies in Second Language Acquisition, 13, 377-393.

Everett, D. (1996). Syllable integrity. Ms., University of Pittsburgh.

Gilbert, J. (2005). Clear speech: Pronunciation and listening comprehension in North American English (2 ${ }^{\text {nd }}$ Ed.). Oxford: Cambridge University Press.

Goad, H. \& Kang, H. S. (2003). Word-final syllabification in L2 acquisition with emphasis on Korean learners of English. In J. Liceras et al. (Eds.), Proceedings of the 6th Generative Approaches to Second Language Acquisition Conference, 122129.

Hardison, D. (2004). Generalization of computer-assisted prosody training: quantitative and qualitative findings. Language Learning \& Technology, 8, 34-52.

Heyer, S. (1986). English final consonants and the Chinese learner. MA Thesis, Southern Illinois University. 
Jensen, J. (1977). Yapese reference grammar. Honolulu: University of Hawaii Press.

Labov, W. (1966). The social stratification of English in New York City. Washington, DC: Center for Applied Linguistics.

Lambacher, S. (1999). A CALL tool for improving second language acquisition of English consonants by Japanese learners. Computer Assisted Language Learning, 12, 137-156.

Leopold, W. (1939). Speech development of a bilingual child: A linguist's record. New York: AMS Press.

Major, R. (1994). Chronological and stylistic aspects of second language acquisition of consonant clusters. Language Learning, 44, 655-80.

Major, R. (2001). Foreign accent: The ontogeny and phylogeny of second language phonology. Mahwah, New Jersey: Lawrence Erlbaum.

Miller, S. (2000). Targeting pronunciation: The intonation, sounds, and rhythm of American English. Boston, MA: Houghton Mifflin.

Pintzuk, S. (1988). VARBRUL program [computer program]. Philadelphia: University of Pennsylvania Department of Linguistics.

Prince, A. \& Smolensky, P. (1993). Optimality theory: Constraint interaction in generative grammar. Cambridge, Massachusetts: MIT Press.

Prator, C. \& Robinett, B. (1972). Manual of American English pronunciation. (3 ${ }^{\text {rd }}$ ed.) New York: Holt, Rinehart \& Winston.

Rose, Y. (2000). Headedness and prosodic licensing in the L1 acquisition of phonology. $\mathrm{PhD}$ thesis, McGill University.

Silveira, R. (2007). The role of task-type and orthography in the production of wordfinal consonants. Revista de Estudos da Linguagem, 15, 143-176.

Tarone, E. (1985). Variability in interlanguage use: A study of style-shifting in morphology and syntax. Language Learning 35,373-403.

Taylor, L. (1993). Pronunciation in action. Englewood Cliffs: Prentice Hall. 
Tzacosta, M. (2003). Morpho-phonological conflicts in the acquisition of stress in Greek. Paper presented at Generative Linguistics in the Old World (GLOW 2003).

Ussishkin, A. (2000). The emergence of fixed prosody. PhD dissertation, UC Santa Cruz.

Wang, C. (1995). The acquisition of English word-final obstruents by Chinese speakers. $\mathrm{PhD}$ dissertation, SUNY at Stony Brook.

Zhang, F. (2005). Making feedback last: An integrated approach to feedback in language learning. In J.-B. Son (Ed.), Computer-assisted language learning: Concepts, contexts and practices (pp. 145-164). Lincoln, NJ: APACALL Book, iUniverse. 